\title{
Study on instability failure mode and monitoring early warning standard of surrounding rock in fully weathered argillaceous sandstone section of large section tunnel
}

\author{
Ming Zhao ${ }^{1,2}$, Ke $\mathrm{Li}^{2 *}$, Hong Yan $\mathrm{Guo}^{2}$ and KaiCheng Hua ${ }^{1}$ \\ ${ }^{1}$ Guangdong Road and Bridge Construction Development Co., Ltd., Guangzhou, 510000, China \\ ${ }^{2}$ China Merchants Chongqing Communications Technology Research \& Design Institute Co., Ltd, Chongqing,400000, China
}

\begin{abstract}
Based on the special geological conditions of a tunnel in Qingyuan section of Huizhou-Zhanzhou Expressway, FLAC3d numerical simulation software is used to simulate the rheological properties and instability of surrounding rock in large-section fully weathered sandstone section, and the stability and loss of surrounding rock are analyzed. The deformation of the dome and the face at steady state is analyzed. It is found that: 1) when the surrounding rock is in a stable state, the deformation curve of the dome is smooth. When the surrounding rock of the face is unstable, the front of the face appears ahead. Deformation should be first strengthened on the surrounding rock in front of the face. 2) The arched foot is an important part of the instability of the surrounding rock. In order to prevent the expansion of the collapsed part, the arched part should be reinforced. 3) In order to obtain the limit state of surrounding rock stability, the strength of surrounding rock is reduced, and the strength reduction coefficient corresponding to the displacement sudden point is taken as the safety factor of rock stability around the hole, and the stability safety coefficients of surrounding rock of each construction step are greater than 1.2. 4) The dynamic standard values of deformation control in the whole construction stage are obtained by analyzing the deformation curves of each data monitoring point with time in the corresponding time period of each construction step.
\end{abstract}

\section{Introduction}

With the increase of excavation area of large-section tunnels, the construction difficulty also increases sharply. Especially in the process of excavation of fully weathered argillaceous sandstone, stress concentration is easy to occur at the bottom corner of the excavation, and the surrounding rock conditions are poor and the loose load Larger, the force during construction is more unfavorable. Determining the surrounding rock failure mode of the fully weathered argillaceous sandstone section of large-section tunnel is to ensure construction safety, construction progress and prevention of landslide. [1-3].

Domestic and foreign scholars have carried out more research on the instability and monitoring and early warning of surrounding rock in large-section tunnels. Liang Xiaoyong and others rely on the Lanzhou-Lanyu Railway Loess Tunnel. The indoor model test shows that the instability process of the loess tunnel is divided into four. At the stage, and with the increase of the load, the radial stress in the loose area of the arch increases first and then decreases, and the stress at other measuring points increases, while the tangential stress exists in the deep part of the surrounding rock [4]. Ma Shiwei et al. relied on the large-section shallow-buried loess tunnel, and proposed the idea and method of real-time early warning of tunnel collapse. The establishment principle and grading standard of tunnel anti-collapse warning base value were given, and the tunnel anti-collapse warning system was developed to realize the tunnel. Internal collapse warning [5].

Combined with the special geological conditions of a tunnel in Qingyuan section of Huizhou-Zhanzhou Expressway, the numerical simulation software is used to simulate the rheological behavior and instability failure of the surrounding rock in the large-section fully weathered sandstone section. The deformation of the dome and the face of the wall under the steady state and the unstable state of the surrounding rock are analysed, analysis of the failure mode of surrounding rock failure. And through the study of the displacement deformation at the monitoring point around the hole, the stability safety factor of surrounding rock under the limit state of surrounding rock stability is obtained. By analyzing the deformation curves of each data monitoring point in the corresponding time period of each construction step, the dynamic standard value of deformation control in the whole construction stage can be obtained [6].

*Corresponding author's e-mail: 364842342@qq.com 


\section{Project Profile}

\subsection{Lining Cavity and Its Classification}

The Qingyuan section of Huizhou City, Yuzhan Expressway is located in the central part of Guangdong Province. The Taihedong tunnel has a starting and ending mileage of $\mathrm{K} 173+752 \sim \mathrm{K} 178+040$ and a length of $4298 \mathrm{~m}$. The exit section of the tunnel is fully weathered sandstone, and the rock mass is rich in water. During the tunnel construction process, the stability of the surrounding rock is poor and it is easy to collapse. During the tunnel construction process, the surrounding rock deformation is large, the deformation rate is fast, and some initial support structures are cracked.

\section{Numerical analysis of instability failure mode of fully weathered sandstone tunnel}

\subsection{Calculation model establishment}

In this numerical simulation, FLAC3D software is used to establish a plane model to analyze the stability and failure modes of surrounding rock rheological properties of fully weathered sandstone section of Huiqing high-speed Taihe Tunnel. It is assumed that the surface and soil layers are stratified, homogeneous and horizontally distributed, and the formation material is calculated by Mohr-Coulomb yield criterion. The stress and strain of stratum and material change in the

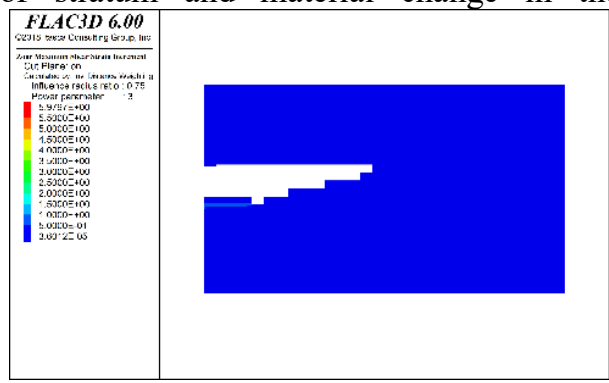

(a) steady state elastic-plastic range. The tunnel is excavated by three-bench seven-step excavation method. Considering the coupling effect of surrounding rock and lining stress, the mesh around the tunnel and the parts concerned is refined and shell element is used in the initial support. The upper part of the model is taken to the surface, the free boundary, the bottom and the left and right boundary are taken 5 times the diameter of the tunnel respectively, and the fixed boundary. When calculating, the standard three-bench seven-step method is formed by excavating step by step, and the tunnel is excavated in the back cycle. The numerical calculation model of the tunnel is shown in Figure 1.

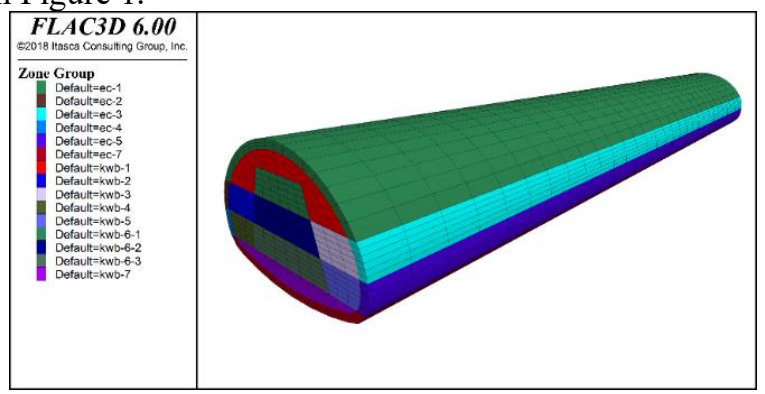

Fig. 1 Three-dimensional numerical analysis model

\subsection{Analysis of ultimate strain of surrounding rock instability}

The maximum shear strain under various working conditions was extracted for comparative analysis. Figure 2 shows the instability failure mode of surrounding rock in fully weathered sandstone formation tunnel.

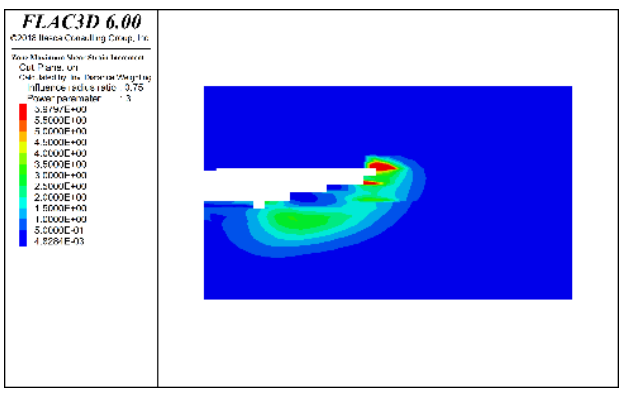

(b) unstable state

Fig.2 Maximum shear strain cloud diagram of surrounding rock during tunnel construction

Figure 2 shows the fully weathered sandstone section of the Taihedong tunnel. The arch foot is the weak link of surrounding rock instability. It gradually extends to the vault part, and eventually collapses. The whole surrounding rock of the face of the face slides out of the shear failure. In order to control the deformation of surrounding rock, it is necessary to reinforce the arch foot part. At the same time, the effective step length should be ensured to ensure the safety of tunnel instability.

\section{Monitoring and warning standards for construction excavation of tunnels in fully weathered sandstone formations}

\subsection{Monitoring point arrangement}

Taking the displacement of the monitoring data of the hole data as the criterion of the instability of the surrounding rock, the strength reduction coefficient corresponding to the displacement point is taken as the stability safety factor of the tunnel surrounding rock, so as to study the dynamic evolution law of the tunnel stability during the construction period. The data point layout is shown in Figure 3. 


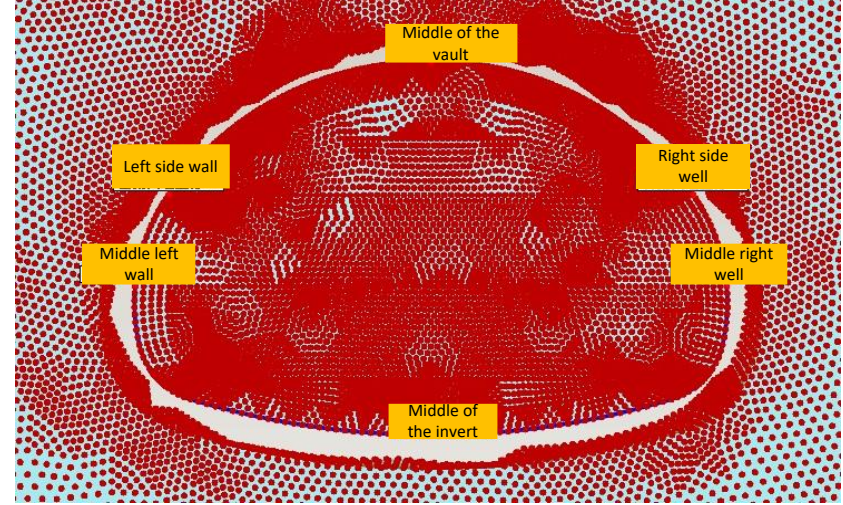

Fig.3 data point diagram

\subsection{Surrounding rock stability safety factor}

In order to obtain the limit state of surrounding rock stability, the strength of surrounding rock is reduced until the surrounding rock is subjected to stability failure, and the lower arch settlement of different reduction factors is extracted for analysis, and the strength reduction coefficient corresponding to the displacement sudden point is taken. As a safety factor of rock stability around the cave, when the sudden change of the curve of the midpoint of the dome is not obvious, the comprehensive determination of the stability factor can be determined by the mutation on the curve of the deformation of other data monitoring points on the curved wall.

According to the above method, the dynamic evolution law of surrounding rock stability during construction can be obtained, as shown in Table 1 .

Table 1 Rock stability safety factor around the hole corresponding to each construction step

\begin{tabular}{lccccccc}
\hline Construction process & $\begin{array}{c}\text { First } \\
\text { piece }\end{array}$ & $\begin{array}{c}\text { Second } \\
\text { piece }\end{array}$ & $\begin{array}{c}\text { Third } \\
\text { piece }\end{array}$ & $\begin{array}{c}\text { Fourth } \\
\text { piece }\end{array}$ & $\begin{array}{c}\text { Fifth } \\
\text { piece }\end{array}$ & $\begin{array}{c}\text { Sixth } \\
\text { piece }\end{array}$ & $\begin{array}{c}\text { Seventh } \\
\text { piece }\end{array}$ \\
\hline Stable safety factor & 1.50 & 1.40 & 1.34 & 1.28 & 1.24 & 1.24 & 1.22 \\
\hline
\end{tabular}

\subsection{The surrounding rock deformation with the construction step dynamic safety control reference value}

According to the above research on the dynamic evolution law of surrounding rock stability during construction, it can be seen that the stability safety factor of surrounding rock in each construction step is greater than 1.20. Combined with the current research results on the safety factor of surrounding rock after initial lining, it is generally recommended to ensure that the safety factor after initial lining is greater than 1.20 to ensure the safety of tunnel construction.

According to calculate the slope of the approximate straight line segment at the front of the curve, the rate of settlement in the middle of the dome and the convergence deformation of the curved wall are obtained, and the corresponding deformation control standard is obtained.

According to the above method, the dynamic standard of deformation control of each construction step during the construction process can be obtained, as shown in Table 2.

Table 2 Dynamic deformation control reference value of tunnel surrounding rock deformation with construction steps

\begin{tabular}{|c|c|c|c|c|c|c|c|c|}
\hline \multirow{2}{*}{$\begin{array}{l}\text { Construction } \\
\text { process }\end{array}$} & \multirow{2}{*}{$\begin{array}{l}\text { Settlement in } \\
\text { the middle of } \\
\text { the vault } \\
(\mathrm{mm})\end{array}$} & \multirow{2}{*}{$\begin{array}{l}\text { Settling rate } \\
\text { in the middle } \\
\text { of the vault } \\
(\mathrm{mm} / \mathrm{d})\end{array}$} & \multicolumn{2}{|c|}{$\begin{array}{c}\text { Horizontal } \\
\text { deformation of the } \\
\text { curved wall }(\mathrm{mm}) \\
\end{array}$} & \multirow{2}{*}{$\begin{array}{l}\text { Curved wall } \\
\text { convergence } \\
\text { rate }(\mathrm{mm} / \mathrm{d})\end{array}$} & \multicolumn{2}{|c|}{$\begin{array}{l}\text { Horizontal deformation } \\
\text { in the middle of the } \\
\text { curved wall }(\mathrm{mm})\end{array}$} & \multirow{2}{*}{$\begin{array}{l}\text { Convergence rate in } \\
\text { the middle of the } \\
\text { curved wall }(\mathrm{mm} / \mathrm{d})\end{array}$} \\
\hline & & & Left side & $\begin{array}{l}\text { Right } \\
\text { side }\end{array}$ & & Left side & $\begin{array}{l}\text { Right } \\
\text { side }\end{array}$ & \\
\hline First piece & 105.8 & 43.17 & - & - & - & - & - & - \\
\hline $\begin{array}{l}\text { Second } \\
\text { piece }\end{array}$ & 202.9 & 34.37 & 17.23 & - & - & - & - & - \\
\hline $\begin{array}{l}\text { Third } \\
\text { piece }\end{array}$ & 232.7 & 28.95 & 19.92 & 7.45 & 15.52 & - & - & - \\
\hline $\begin{array}{l}\text { Fourth } \\
\text { piece }\end{array}$ & 280.2 & 25.90 & 34.44 & 12.78 & 13.19 & 87.22 & - & - \\
\hline $\begin{array}{l}\text { Fifth } \\
\text { piece }\end{array}$ & 328.1 & 20.49 & 42.36 & 25.46 & 11.36 & 115.57 & 101.06 & 25.75 \\
\hline $\begin{array}{l}\text { Sixth } \\
\text { piece }\end{array}$ & 372.9 & 18.28 & 52.16 & 35.40 & 10.07 & 139.42 & 131.44 & 21.38 \\
\hline $\begin{array}{l}\text { Seventh } \\
\text { piece }\end{array}$ & 376.9 & 16.42 & 54.43 & 36.26 & 9.64 & 143.28 & 134.72 & 13.61 \\
\hline
\end{tabular}

Note: The "first block" means "the first piece of excavation and the initial lining is completed". 


\section{Conclusion}

In this chapter, through the indoor test and numerical limit analysis of surrounding rock mechanical properties, the surrounding rock stability, instability failure mode and monitoring and early warning standards of the fully weathered sandstone section of Taihe tunnel are studied, and the following conclusions are obtained:

1) Through three-dimensional numerical simulation analysis, the arched part of the fully weathered sandstone section of the Taihe tunnel of Huiqing Expressway is the weak link of the instability of the surrounding rock during the construction process, gradually expanding to the top of the arch, and finally collapses and collapses. The overall slippage of the surrounding rock is destructive. In order to control the deformation of the surrounding rock, it is necessary to reinforce the arch portion. At the same time, the effective step length should be ensured to ensure the tunnel is unstable and safe.

2) Based on the numerical limit analysis, the control safety factor (1.2), the accumulative value of deformation and the safety datum value of deformation rate under the condition of rich water in fully weathered sandstone section of large cross-section tunnel are proposed.

\section{Acknowledgments}

National Key Research and Development Plan of China (2017YFC08060010, 2017YFC08060003), This work is financially supported by Security Science and Technology Innovation Project for Social Undertakings and People's Livelihood Guarantee in Chongqing, China (cstc2017shmsA30010), Project of the National Natural Science Foundation of China (41601574).

\section{Reference}

1. Li X., Xu Z. (2017) Analysis of Highway Tunnel Construction Automation Monitoring Technology[J]. Journal of Highway and Transportation Technology (Apps \& Technology Edition), 13(04): 159-161.

2. Xu J.g., Feng H.b. (2016) Research on Real-time Monitoring and Early Warning System of Tunnel Lining Deformation and Seasonal Deformation Law $[\mathrm{J}]$. Journal of Highway and Transportation Technology, 12(06):261-263.

3. Zuo Q.J., Wu L., Lu Z.W., Tan Y.Z., Yuan Q. (2015) A theoretical analysis of instability and instability of weak surrounding rock in shallow tunnel section[J]. Rock and Soil Mechanics,36(S2):424 -430.

4. Liang X.Y., Pei S.M., Zhang C.H. (2013) Experimental study on instability of surrounding rock of deep buried large-section loess tunnel[J]. Chinese Journal of Geotechnical Engineering, 35(S2): 559-563.
5. Ma S.W., Han X.Q., Liao K. (2014) Real-time monitoring and early warning of anti-collapse of shallow-buried large-section loess tunnel[J]. Modern Tunnel Technology,51(02):11-15+22.

6. Song R.G., Zhang D.L., Wen M. (2015) A catastrophic theoretical analysis of the instability of surrounding rock in a deep tunnel through fault fracture zone[J]. China Civil Engineering Journal, 48(S1): 289-292. 